\title{
PLURALITAS MASYARAKAT DALAM ISLAM
}

\section{Joko Widodo}

STAI AL Muhammad Cepu

Email: joko.widodo021@gmail.com

\begin{abstract}
Abstrak
Plurality is a fact and can not be denied in society, Islam as a moderate religion, which a justice, and always invites people to facilitate religious and possess compassion for fellow human beings. Islam rejects the conservative attitudes, opacity, and setbacks. On the other hand, Islam also rejects definitively all forms of oppression, hostility, murder, and destruction (on behalf of unifying the Ummah). All humans in the natural world was created from the same origin. No excess of one than the other, but the most good in the discharge of its functions sebagimana caliph of God on earth, which is more useful for humanity, and the most piety to Allah SWT. Differences of race and nation merely as a sign and identity in social life of society. Islam recognizes the plurality, as in Q.S. Al-Hujurat verse; 13. Islam recognizes the differences in nation, tribe, ethnicity and language. This diversity can not be deleted. But Islam is able to cope with this diversity or differences.
\end{abstract}

Keywoard: Pluralitas Masyarkat, Islam

\section{A. Pendahuluan}

Islam adalah agama rahmatal lilalamin, yang membawa misi kedamaian. Dinul Islam bukan untuk golongan atau sekte-sekte akan tetapi untuk seluruh umat manusia di alam dunia ini. Tokoh utama yang memainkan peranan sangat penting dan signifikan dalam proses penyiaran dan penyebaran Islam yang berlangsung secara spektakuler itu ialah Nabi Muhammad Saw (lahir tahun 571).

Ia mendapatkan dukungan penuh dari para sahabatnya secara setia dan terpecaya. Kemunculan Islam dan kebangkitan Islam di Mekkah dan penyebaranya secara cepat dan luas di Arabia Memiliki signifikan tersendiri di mata para sejarawan terutama perkembngan Islam samapai kedunia barat

Islam adalah agama moderat, agama yang berasaskan sebuah keadilan, membenci tatharruf (tidak berhati-hatidi dalam masalah agama) dan ghuluw (terlalu mengada-ngada di dalam masalah 
agama), dan selalu mengajak manusia untuk mempermudah agama dan memiliki kasih sayang kepada sesama manusia. Islam menolak sikap konservatif, ketertutupan, dan kemunduran. Di sisi lain, Islam juga menolak secara pasti segala macam bentuk penindasan, permusuhan, pembunuhan, dan penghancuran ${ }^{1}$

Sesungguhnya Islam memberikan pencerahan terhadap kehidupan, hal ini dalam kehidupan duniawi untuk menuju kehidupan ukhrowi. Yakni kehidupan di dunia tentu hidup bermasyarakat, yang semuanya majemuk, beraneka ragam, heterogenitas hal itu, merupakan sunnatullah yang harus disikapi dengan bijaksana. Islam merupakan tatanan yang cocok dalam berkehidupan bermasyarakat dan berbangsa. Sehingga perkembangan Islam banyak diterima oleh masyarakat baik nasional maupun masyarakat dunia. Islam tidak membeda-bedakan antara ras, warna kulit, kulit hitam atau kulit putih, tetapi menjaga kerukunan.

Masyarakat yang bercorak pluralitas menyebabkan setiap golongan memiliki cara berfikir dan bertindak sendiri dalam mewujudkan kepentingan menurut filosofi hidupnya yang dipengaruhi oleh keyakinan, kultur dan situasi. Menurut para pemikir muslim, seperti Ibn Abi Rabi', Al-Mawardi dan Ibn Khaldun menyatakan bahwa untuk mewujudkan masyarakat teratur diperlukan tercipanya rasa aman, damai, keadilan yang menyeluruh yang didasarkan pada undang-undang untuk mengatur kerjasama antar kelompok sosial yang menjamin kepentingan bersama serta didukung oleh pemimpin yang berwibawa untuk melaksanakanya ${ }^{2}$

Semua manusia di alam dunia diciptakan dari satu asal yang sama. Tidak ada kelebihan yang satu dari yang lainya, kecuali yang paling baik dalam menunaikan fungsinya sebagimana khalifah Tuhan di bumi, yang lebih banyak manfaatnya bagi kemanusiaan, dan yang paling takwa kepada Allah SWT. Perbedaan ras dan bangsa hanyalah sebagai pertanda dan identitas dalam pergaulan Internasional. Sebagimana firman Allah dalam Al Qur'an Surat Al Hujurat ayat 13 yang artinya:

Hai manusia! Sesungguhnya Kami menjadikan kamu dari seorang laki-laki dan perempuan dan Kami menjadikan kamu berbangsa-bangsa, supaya kamu saling kenal-mengenal dengan baik, sesungguhnya semulia-mulia kamu pada sisi Allah ialah yang paling takwa(Q.S Al Hujurat:13)

Islam menegaskan prinsip persamaan seluruh manusia. Atas dasar prinsip persamaan itu, maka setiap orang mempunyai hak dan kewajiban yang sama. Islam tidak memberikan hak-hak istimewa bagi seseorang atau golongan lainya, baik dalam bidang kerohanian, maupun dalam bidang politik,sosial dan ekonomi. Jadi setiap orang mempunyai kedudukan atau kewajiban yang sama atas kesejahtraan anggotanya. Sebab Islam menentang setiap bentuk diskriminasi, baik diskriminasi karena keturunan, maupun karena warna kulit, kesukuan, kebangsaan dan kekayaan. ${ }^{4}$

1 Mamud Hamdi Zaqzuq, Islam dan Tantangan dalam Menghadapi Pemikiran Barat, Penerjemah Ahmad Sodikin, 2003, CV Pustaka Setia, Bandung hal.43

2 M.Tuwah, subardi Dkk, Islam Humanis, 2001,PT Moyo Segoro Agung Jakarta hal. 17

3 Departemen Agama, 1992, Al Quran dan Terjemahanya,Departemen Agama RI

4 Nasruddin Razak, Dienul Islam, 1973, PT Al Ma’arif ,Bandung hal. 28 
Islam adalah agama rahmat bagi seluruh umat dan alam semesta. Oleh karena itu, ia tidak mengajarkan sikap individualisme dan tidak membenarkan sikap fanatisme yang berlebihan. Justru sebaliknya, Islam mengajarkan kebersamaan dalam keberbedaan, dan menjujung tinggi persaudaraan (al-ukhuwah) antar sesama. Maka tidak ada alasan untuk hidup saling bermusuhan. Yang ada adalah sikap kasih kasang antar sesama manusia agar terbentuk tatanan masyarakat yang gotong royong dan saling membantu atas dasar kecintaan. Dari sini akan terasa aman di atas muka bumi ini. ${ }^{5}$

Ajaran Islam pada hakekatnya adalah ajaran bagi kepemimpinan dan kesejahtraan dunia. Salah satu cirinya yang paling penting ialah, ia mengajarkan kepada para penganutnya, bagimana memperoleh kepercayaan diri tanpa dinodai kesombongan dan mementingkan diri sendiri, kepada Islam menghembuskan semangat agama dan keyakinan, bebas dari penipuandiri,dan memisahkan ia dari segala ketergantungan pada orang lain, kepada Islam menanamkan keimanan yang sempurna terhadap Allah SWT . keimanan ini menugaaskan umat Islam memikul tanggung jawab kemanusiaan semampu mungkin dan mendorongnya menjadi wakil bagi semua bangsa manusia $^{6}$

\section{B. Makna Pluralitas dan pluralisme}

Pluralitas dengan Pluralisme kelihatanya hampir sama tetapi berbeda. Pluralitas adalah kondisi keberagaman. Sedangkan pluralisme, akar kata dari plural. Plural berasal dari bahasa Inggris plural bermakana jamak atau lebih dari satu. Jadi pluralisme adalah hal yang mengatakan jamak atau lebih dari satu. Dalam kajian filosofis, pluralisme diberi makna sebagai doktrin bahwa subtansi hakiki itu satu (monoisme), tidak dua (dualisme), akan tetapi banyak (jamak) ${ }^{7}$. Menurut Kamus Besar Bahasa Indonesia Pluralisme adalah keadaan masyarakat yang majemuk (bersangkutan dengan sistem sosial dan politiknya) ${ }^{8}$

Kata pluralitas jelas artinya adalah ada banyak macam, ada perbedaan, ada keanekaan. Pluralitas mengungkapkan fakta bahwa ada banyak. Sedangkan pluralitas keagamaan artinya ada aneka agama dan orientasi keagamaan. ${ }^{?}$

Kata "pluralisme" berasal dari bahasa Inggris, pluralism. Kata ini diduga berasal dari bahasa Latin, plures, yang berarti beberapa dengan implikasi perbedaan. Pluralisme adalah pandangan fiolosofi yang tidak mau mereduksi segala sesuatu pada satu prinsip terakhir, tetapi menerima adanya keragaman ${ }^{10}$. Sedangkan Pluralitas dimaknai dengan keberagaman.

Dari asal-usul kata ini diketahui bahwa pluralisme agama tidak menghendaki keseragaman

5 Mundzier Suparta, 2008, Islamic Mulicultural Education Sebuah Refleksi atas Pendidikan Agama Islam di Indonesia,Al-Ghazali Center, Jakarta, hlm.57

6 Abul Hasan Ali Nadwi, 2008, Islam dan Dunia, Penerjemah Drs. Adang Affandi, Angkasa Bandung hlm. Xi

7 M. Tuwah, Subardi Dkk, 2001, Islam Humanis, PT Moyo Segoro Agung Jakarta hlm. 42

8 Departemen Pendidikan Nasional, 2005, Kamus Besar Bahasa Indonesia, Edisi ketiga, Balai Pustaka, Jakarta, hal. 883

9 http://www.christianpost.co.id/opini/20090728/4891/pluralitas-keagamaan-asset-atau-liability/

10 Nur Cholis Madjid, 1998, Kebebasan Beragama dan Pluralisme Dalam Islam, dalam Komarudin Hidayat dan Rahma Gous EF, Passing Over, Gramadia, hlm.184 
bentuk agama. Sebab, ketika keseragaman sudah terjadi, maka tidak ada lagi pluralitas agama (religious plurality). Keseragaman itu sesuatu yang mustahil. Allah menjelaskan bahwa sekiranya Tuhanmu berkehendak niscaya kalian akan dijadikan dalam satu umat. Pluralisme agama tidak identik dengan model beragama secara eklektik, yaitu mengambil bagian-bagian tertentu dalam suatu agama dan membuang sebagiannya untuk kemudian mengambil bagian yang lain dalam agama lain dan membuang bagian yang tak relevan dari agama yang lain itu.

Allah berfirman:

"Allah tidak melarang kamu untuk berbuat baik dan berlaku adil terhadap orang-orang yang tidak memerangi dalam urusan agama dan tidak pula mengusir kamu dari negerimu. Sesungguhnya Allah menyukai orang-orang yang berlaku adil". QS, al-Mumtahanah [60]: Ayat 8

Dengan menggunakan dasar pemahaman tentang pluralisme seperti di atas, maka dapat diidentifikasikan sekurang-kurangnya lima ciri utama pluralisme:

1. Selau berkaitan dengan memelihara dan menjunjung tinggi hak dan kewajiban masingmasing kelompok

2. Menghargai perbedaan dalam kebersamaan

3. Pluralime menunjukan kepada wahana untuk mengembangkan dan meningkatkan kemampuan berkompetisi secara jujur, terbuka, dan adil, karakteristik ini berkaitan dengan upaya menghilangkan pendapat bahwa dalam kehidupan bermasyarakat ada kelompok ordinate yang mendominasi kelompok subordinate, kelompok mayoritas merasa lebih unggul dari kelompok minoritas

4. Pluralisme harus didudukan pada posisi yang proporsional. Yang berarti bahwa pluralisme dicirikan oleh pandangan-pandangan yang berbeda yang nampak menjadi daya dorong untuk mendinamisasi kehidupan bermasyarakat, dan bukan mekanisme untuk menghancurkan satu kelompok terhadap kelompok lain.

5. Menunjukkan adanya perasaan kepemilikan bersama, untuk kepentingan bersama dan diupayakan bersama. ${ }^{11}$

Jadi berdasarkan pada paparan di atas dapat diartikan, bahwa pluralisme agama adalah suatu sistem nilai yang memandang keberagaman atau kemajemukan agama secara positif sekaligus optimis dengan menerimanya sebagai kenyataan (sunnatullâh) dan berupaya untuk berbuat sebaik mungkin berdasarkan kenyataan itu.

Dikatakan secara positif, agar umat beragama tidak memandang pluralitas agama sebagai kemungkaran yang harus dibasmi. Dinyatakan secara optimis, karena kemajemukan agama itu sesungguhnya sebuah potensi agar setiap umat terus berlomba menciptakan kebaikan di bumi. Seperti yang termaktub dalam Al qur'an: berlomba-lombalah dalam hal kebajikan.

Jadi berdasarkan uraian diatas, Pluralitas dan Pluralisme dapat dibedakan yaitu, Kata pluralitas jelas maknanya, ada banyak macam, ada perbedaan, ada keanekaan atau keanekaragaman. Pluralitas mengungkapkan fakta bahwa ada banyak. Sedangkan pluralitas 
keagamaan artinya ada aneka agama dan orientasi keagamaan.

Sebaliknya, kata pluralisme (pluralisme sendiri adalah sikap mendukung pluralitas) bisa dipakai dalam beberapa arti (meskipun sebaiknya tidak), terutama dalam arti dogmatis dan dalam arti sosial.

Dalam arti dogmatis, pluralisme dapat berarti: anggapan bahwa semua agama adalah sama saja. Dan bahwa orang dari semua agama bisa masuk surga. (Hanya) dalam arti ini MUI mengharamkan pluralisme.

Akan tetapi penggunaan kata pluralisme dalam arti dogmatis ini sebaiknya dihindari. Anggapan bahwa semua agama sama saja, sebenarnya justru menghilangkan pluralitas (dan memang bertentangan baik dengan agama Islam maupun Kristiani). Anggapan itu sebaiknya disebut "relativisme agama" karena merelatifkan kebenaran agama (sama dengan mengatakan bahwa semua agama hanya benar bagi para penganutnya, sedangkan "secara objektif" tak ada yang lebih benar dari yang lain). ${ }^{12}$

\section{Pluralitas dalam Islam}

a. Dalam Al Qur'an

Secara implisit, dalam Al qur'an ada beberapa ayat yang isinya mengarah apada nilai-nilai pluralitas, misalnya:

1) Surat Al Hujarat ayat 13

"Hai manusia, sesungguhnya Kami menciptakan kamu dari seorang laki-laki dan seorang perempuan dan menjadikan kamu berbangsa-bangsa dan bersuku-suku supaya kamusaling kenal mengenal. Sesungguhnya orang yang paling mulia di antara kamudi sisi Allah ialah orang yang paling bertaqwa di antara kamu. (Qs. Al Hujarat ayat 13)

2) Surat Al Baqoroh Ayat 256

"Tidak ada paksaan untuk (memasuki) agama (Islam); sesungguhnya telah jelas jalan yang benar daripada jalan yang sesat.(Qs. Al Baqoroh Ayat 256).

3) Surat Yunus Ayat 99 :

"Dan jikalau Tuhanmu menghendaki, tentulah beriman semua orang yang di muka bumi seluruhnya.(Qs. Yunus Ayat 99)

4) Surat Al Kafirun Ayat 6:

"Untukmu agamamu, dan untukulah agamaku.(Qs. Al Kafirun Ayat 6)

5) Surat Al Maidah ayat 65:

"Sesungguhnya orang-orang yang beriman, orang-orang Yahudi, shabiin, dan orang-orang Nasrani, barang siapa beriman kepada Allah, kepada hari kemudian dan berbuat kebajikan, maka tidak ada rasa khawatir padanya dan mereka tidak bersedih hati.(Qs. Al Maidah ayat 65)

6) Surat Al Mumtahanah ayat 9

"Sesungguhnya Allah hanya melarang kamu menjadikan sebagai kawanmu orang-orang 
yang memerangimu karena agama dan mengusir kamu dari negerimu, dan membantu (orang lain) untuk mengusirmu. (Qs. Al Mumtahanah ayat 9)

b. Dalam Hadist Nabi Saw

Imam Bukhari meriwayatkan dalam kitab janazah (1229):

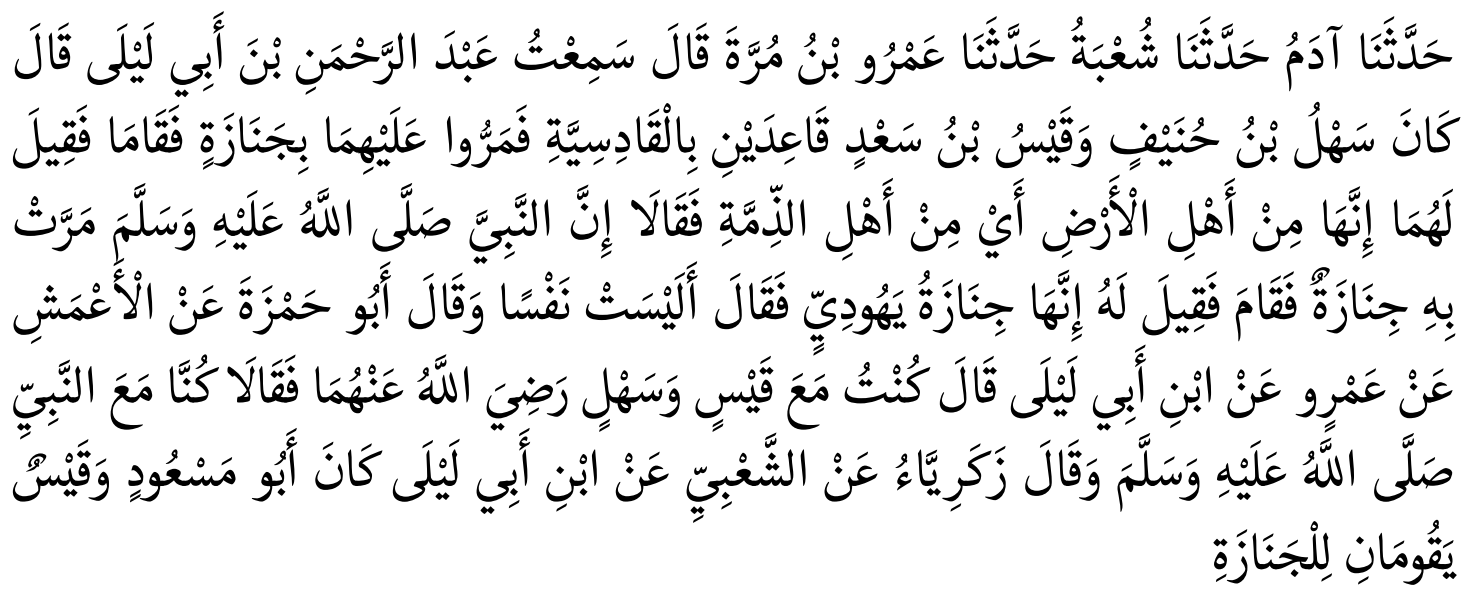

Artinya: "Pada suatu saat telah dibawa seorang jenazah, kemudian Nabi berdiri, lalu ada yang mengatakan kepada Nabi bahwa jenazah tersebut adalah seorang Yahudi, maka Nabi bersabda; bukankah dia juga jiwa?, "

Ini berarti bahwa jiwa manusia mempunyai kehormatan dan kedudukan, apapun agama yang dianutnya.

Dalam sebuah riwayat Ibnu Abbas berkata: " balaslah salam kepada siapa saja, baik Yahudi, Nasrani, atau Majusi, hal itu karena Alla berfirman : "Apabila kamu dihormati dengan suatu penghormatan, maka balaslah penghormatan itu dengah lebih baik, atau balaslah dengan yang serupa" (surat al-Nisa': 86). Diceritakan pula bahwa suatu hari ada seorang Majusi bersalam kepada Nabi, lalu Nabi menjawab salamnya seraya berkata; "Dan bagimu keselamatan dan rahmat Allah". Sebagian orang yang ikut bersama beliau bertanya; "Engkau mengucapkan "dan ramat Allah bagimu"? "Nabi menjawab: "Bukankah dalam rahmat Allah ia dapat hidup.

Jadi Islam mengakui pluralitas, sebagaimana dalam Al Qur'an dan Hadist tersebut. Islam mengakui adanya perbedaan bangsa dan suku, etnis dan bahasa. Keragaman ini tidak bisa dihapus. Tapi Islam mampu mengatasi keragaman atau perbedaan ini. Dari mana? Yang pertama, Islam ditujukan bagi seluruh umat manusia. Dalam QS Al A'raf:158: Qul Yaa ayyuhannaas, innii Rasuulullaahi ilaikum jamiian: Wahai sekalian manusia, sesungguhnya aku (Muhammad) adalah utusan Allah untuk kami semua.Ini menunjukkan bahwa syariat Allah adalah untuk seluruh umat manusia. Kalau Allah Swt yang mengatakan demikian mengapa kita ragu? Kita inikan berasal dari Allah, orang Amerika, Inggris, Afrika, Indonesia, semuanya Allah yang menciptakan. Tidak masalah-kan, kalau Allah juga yang mengatur dan punya aturan terbaik. Kalau semua manusia di dunia ini mati, kembalinya kan juga kepada Allah. Mengapa kita ragu, bahwa hanya aturan Allah yang terbaik dan menyelamatkan kita semua? Yang kedua, bukti Islam mampu mengatasi keragaman adalah pernah diterapkannya Islam ke seluruh 
masyarakat. Pada abad ke-8 hingga awal abad ke-20, Islam meliputi tiga benua. Sewaktu itu di bawah kepemimpinan Bani Umayyah hingga Bani Utsmaniyah. Di Andalusia (kini Spanyol dan Portugis), Islam menaungi tiga umat. Yaitu Yahudi, Nasrani dan Islam. Demikian juga di Yerusalem dan seluruh bagian dunia Islam, termasuk di Indonesia. Saat itu berbagai suku, etnis, bahkan agama, hidup berdampingan secara damai.

Berdasarkan Nash-nash Al qur'an tersebut di atas, juga dapat diketahui bahwa Allah SWT menciptakan makhluk-Nya (manusia) tidak hanya berupa satu bangsa, suku/golongan, akan tetapi berbangsa-bangsa, bernegara-bernegara dan sebagainya, supaya mereka dapat menjalin melakukan interaksi saling kenal-mengenal di antara mereka.

Di samping itu, diberi hak kebebasan/tidak ada paksaan dalam beragama (masuk agama Islam). Karena hal itu sudah jelas mana jalan yang benar atau yang tersesat. Dan juga dikatakan bahwa baik itu orang-orang Yahudi, Shabiin dan Nasrani bila beriman kepada Allah SWT dan hari akhir/kemudian serta berbuat kebajikan, maka tidak ada kawatiran padanya dan itupun semua urusan Allah SWT. Oleh karena itu, kita dapat mengakui keberadaan keanekaragaman, heterogenitas, baik secara mikro (lokal) sampai secra makro (masyarkat Dunia/Internasional) itu merupakan kenyataan dan sunnatullah.

c. Sikap terhadap Non-Muslim

Pluralitas agama dan umat beragama adalah kenyataan. Sebelum Islam datang, di tanah Arab sudah muncul berbagai jenis agama, seperti Yahudi, Nashrani, Majusi, Zoroaster dan Shabi'ah. Suku-suku Yahudi sudah lama terbentuk di wilayah pertanian Yatsrib (kelak disebut sebagai Madinah), Khaibar, dan Fadak. Di wilayah Arab ada beberapa komunitas Yahudi yang terpencar-pencar dan beberapa orang sekurang-kurangnya disebut Kristen. Pada abad ke empat sudah berdiri Gereja Suriah. Karena itu tak salah jika dinyatakan, Islam lahir dalam konteks agama-agama terutama agama Yahudi dan Nashrani. ${ }^{13}$

Al-Qur'an memiliki pandangan sendiri dalam menyikapi pluralitas umat beragama tersebut.Terhadap Ahli Kitab (meliputi Yahudi, Nashrani, Majusi, dan Shabi'ah), umat Islam diperintahkan untuk mencari titik temu (kalimat sawa'). Kalau terjadi perselisihan antara umat Islam dan umat agama lain, umat Islam dianjurkan untuk berdialog (wa jâdilhum billatî hiya ahsan). Terhadap siapa saja yang beriman kepada Allah, meyakini Hari Akhir, dan melakukan amal kebajikan, al-Qur`an menegaskan bahwa mereka, baik beragama Islam maupun bukan, kelak di akhirat akan diberi pahala. Tak ada keraguan bahwa orang-orang seperti ini akan mendapatlan kebahagiaan ukhrawi. Ini karena, sebagaimana dikemukakan Muhammad Rasyid Ridla, keberuntungan di akhirat tak terkait dengan jenis agama yang dianut seseorang. ${ }^{14}$

Al-Qur'an mengijinkan sekiranya umat Islam hendak bergaul bahkan menikah dengan Ahli Kitab. Tidak sedikit para sahabat Nabi yang memperisteri perempuan-perempuan dari kalangan Ahli Kitab. Utsman ibn `Affan, Thalhah ibn Abdullah, Khudzaifah ibn Yaman, Sa`ad ibn Abi Waqash adalah di antara sahabat Nabi yang menikah dengan perempuan Ahli Kitab.

$13 \mathrm{http}: / /$ islamlib.com/id/artikel/islam-dan-pluralitasisme-agama $14 \mathrm{http}: / /$ islamlib.com/id/artikel/islam-dan-pluralitasisme-agama 
Alkisah, Khudzaifah adalah salah seorang sahabat Nabi yang menikah dengan perempuan beragama Majusi. Nabi Muhammad juga pernah memiliki budak perempuan beragama Kristen, Maria binti Syama'un al-Qibtiyah al-Mishriyah. Dari perempuan ini, Nabi memiliki seorang anak laki-laki bernama Ibrahim. Ia meninggal dalam usia balita. Sejarah juga menuturkan, ayah kandung dari Shafiyah binti Hayy yang menjadi isteri Nabi adalah salah seorang pimpinan kelompok Yahudi.”. ${ }^{15}$

Hal itu dapat digambarkan, Rasul juga hidup bertetangga dengan seorang Nasrani dan biasa saling memberi hadiah makanan. Konon, beliau pernah dihadiahi daging kambing oleh seorang wanita Yahudi, tetangganya. Beliau juga pernah menerima rombongan kaum Nasrani dari Habasyah (Etiopia) di masjid Madinah. Di masjidlah beliau menerima dan menjamu rombongan itu.

Rasul juga pernah menerima rombongan kaum Nasrani dari Najran yang menyampaikan keluhan-keluhanya bahwa agama Nasrani menjadi "terpinggir" setelah kedatangan Islam di Madinah. Nabi Saw pun langsung mengadakan dialog dengan mereka dalam forum yang penuh persaudaraan, sopan santun, dan penuh pengertian. ${ }^{16}$

Sikap perikemanusiaan seperti ini diteladani oleh para khalifah sesudahnya. Tak heran bila banyak para ahli sejarah yang terkagum-kagum dengan budaya dan sikap umat Islam saat itu. Seperti Alan Drapper, misalnya, sejarawan berkebangsaan Amerika ini dengan lantang berseloroh bahwa, kaum muslimin dulu, di masa-masa khalifah, tidak hanya menyertakan ilmuan-ilmuan Nasrani Nestoria dan ilmuan-ilmuan Yahudi dalam masalah pengetahuan sebagai semata-mata kepercayaan untuk melakukan peran-peran penting dan bahkan juga jabatantinggi dalam pemerintahan. Sir Mark Syce juga mensetujui pernyataan Alan, ia mengatakan bahwa pada zaman Harun Ar-rasyid, orang-orang Kristen, Yahudi, Kaum Muslimin dan umat beragama lainya sama-sama mengabdikan dirinya kepada negara. ${ }^{17}$

Pengakuan tentang kenabian Muhammad datang pertama kali dari pendeta Yahudi bernama Buhaira dan tokoh Kristen bernama Waraqah ibn Nawfal. Melalui pendeta Buhaira terdengar informasi, Muhammad akan menjadi nabi pamungkas (khâtam al-nabiyyîn). Buhairâ (kerap disebut Jirjis atau Sirjin) pernah mendengar hâtif (informasi spritual) bahwa ada tiga manusia paling baik di permukaan bumi ini, yaitu Buhaira, Rubab al-Syana, dan satu orang lagi sedang ditunggu. Menurutnya, yang ketiga itu adalah Muhammad ibn Abdillah. Dan ketika Muhammad baru pertama kali mendapatkan wahyu, Waraqah menjelaskan bahwa sosok yang datang kepada Muhammad adalah Namus yang dulu juga datang kepada Nabi Musa. Waraqah mencium kening Muhammad sebagai simbol pengakuan terhadap kenabiannya, seraya berkata, "Berbahagialah, berbahagialah. Sesungguhnya kamu adalah orang yang dikatakan 'Isa ibn Maryam sebagai kabar gembira. Engkau seperti Musa ketika menerima wahyu. Engkau seorang utusan”. Nabi pernah bersabda bahwa Waraqah akan dimasukkan ke dalam surga oleh Allah.

15 http://islamlib.com/id/artikel/islam-dan-pluralitasisme-agama

16 Mundzier Suparta, hal. 84

17 Mundzier Suparta, hal. 85 
Nabi Muhammad tak menganggap ajaran agama sebelum Islam sebagai ancaman. Islam adalah terusan dan kontinyuasi dari agama-agama sebelumnya. Allah berfirman kepada Nabi Muhammad agar ia mengikuti agama Nabi Ibrahim (millat Ibrahim). Sebagaimana Isa al-Masih datang untuk menggenapi hukum Taurat, begitu juga Nabi Muhammad. Ia hadir bukan untuk menghapuskan Taurat dan Injil, melainkan untuk menyempurnakan dan mengukuhkannya. Disebutkan dalam al-Qur'an, "Dia menurunkan al-Kitab (al-Qur'an) kepadamu dengan sebenarnya, membenarkan kitab (mushaddiq) yang telah diturunkan sebelumnya dan menurunkan Taurat dan Injil sebelum al-Qur'an menjadi petunjuk bagi manusia dan Dia menurunkan al-Furqan".

Ini tidak berarti bahwa semua agama adalah sama. Sebab, di samping memang mengandung kesamaan tujuan untuk menyembah Allah dan berbuat baik, tak bisa dipungkiri bahwa setiap agama memiliki keunikan, kekhasan, dan syari atnya sendiri. Sebagian mufasir berkata, al-dîn wâhid wa al-syarî'at mukhtalifat [agama itu satu, sementara syari' atnya berbeda-beda]. Detaildetail syari at ini yang membedakan satu agama dengan agama lain. Sebab, tidaklah mustahil bahwa sesuatu yang bernilai maslahat dalam suatu tempat dan waktu tertentu, kemudian berubah menjadi mafsadat dalam suatu ruang dan waktu yang lain. Bila kemaslahatan dapat berubah karena perubahan konteks, maka dapat saja Allah menyuruh berbuat sesuatu karena diketahui mengandung maslahat, kemudian Allah melarangnya pada waktu lain karena diketahui ternyata aturan tersebut tidak lagi menyuarakan kemaslahatan.

Itulah sikap teologis al-Qur'an dalam merespons pluralitas agama dan umat beragama. Sementara sikap sosial-politisnya berjalan dinamis dan fluktuatif Adakalanya tampak mesra. Di kalayanglain, sangat tegang. Ketika Romawi yang Kristen kalah perang melawan Persia, umat Islam ikut bersedih. Satu ayat al-Qur'an turun menghibur kesedihan umat Islam tersebut. Disebuntkan pula, ketika Nabi Muhammad SAW mengadakan perjalanan ke Thaif, ia bertemu seorang budak pemeluk agama Kristen bernama 'Uddâs di Ninawi Irak (kota asal Nabi Yunus). Ketika Nabi Muhammad Saw dikejar-kejar, 'Uddâs yang memberikan setangkai anggur untuk dimakan. ${ }^{18}$

Diceritakan, ketika Nabi Muhammad Saw dan pengikutnya mendapatkan intimidasi dan ancaman dari kaum Musyrik Mekah, perlindungan diberikan raja Abisinia yang Kristen. Puluhan sahabat Nabi hijrah ke Abisinia untuk menyelamatkan diri, seperti 'Utsman ibn 'Affân dan istrinya (Ruqayah, puteri Nabi), Abû Hudzaifah ibn 'Utbah, Zubair ibn `Awwâm, Abdurrahman ibn `Auf, Ja `ar ibn Abî Thâlib, hijrah ke Abesinia untuk menghindari ancaman pembunuhan kafir Quraisy. Disaat kafir Quraisy memaksa sang raja mengembalikan umat Islam ke Mekah, ia tetap pada pendiriannya; pengikut Nabi Muhammad Saw harus dilindungi dan diberikan haknya memeluk agama. Sebuah ayat al-Qur'an menyebuntkan, "kalian (umat Islam) pasti mendapati orang-orang yang paling dekat persahabatannya dengan orang-orang Islam adalah orang-orang yang berkata, "sesungguhnya kami orang Kristen". Disebuntkan pula, waktu raja Najasyi meninggal dunia, Nabi Muhammad SAW pun melaksanakan shalat jenazah dan memohonkan ampun atasnya. ${ }^{19}$

$18 \mathrm{http}: / /$ islamlib.com/id/artikel/islam-dan-pluralitasisme-agama

19 Ensiklopedi Tematis Dunia Islam, Dinamika Masa Kini, 2002, Ichtiar Baru van Hoeve, Jakarta, hlm. 214 
Alkisah, Nabi pernah menerima kunjungan para tokoh Kristen Najran yang berjumlah 60 orang. Rombongan dipimpin Abdul Masih, al-Ayham dan Abu Haritsah ibn Alqama. Abu Haritsah adalah seorang tokoh yang disegani karena kedalaman ilmunya dan konon karena beberapa karomah yang dimilikinya. Menurut Muhammad ibn Ja'far ibn al-Zubair, ketika rombongan itu sampai di Madinah, mereka langsung menuju mesjid tatkala Nabi melaksanakan shalat ashar bersama para sahabatnya. Mereka datang dengan memakai jubah dan surban, pakaian yang juga lazim dikenakan Nabi Muhammad SAW. Ketika waktu kebaktian telah tiba, mereka pun tak mencari gereja. Nabi Muhammad memperkenankan rombongan melakukan kebaktian atau sembahyang di dalam mesjid. ${ }^{20}$

Hal yang sama juga dilakukan Nabi pada kalangan Yahudi. Ketika pertama sampai di Madinah, Nabi membuat konsensus untuk mengatur tata hubungan antara kaum Yahudi, Musyrik Madinah, dan Islam. Traktat politik itu dikenal dengan "Piagam Madinah" atau "Miytsâq al-Madînah", dibuat pada tahun pertama hijriyah. Sebagian ahli berpendapat bahwa Piagam Madinah itu dibuat sebelum terjadinya perang Badar. Sedang yang lain berpendapat bahwa Piagam itu dibuat setelah meletusnya perang Badar. Piagam ini memuat 47 pasal. Pasalpasal ini tak diputuskan sekaligus. Menurut Ali Bulac, 23 pasal yang pertama diputuskan ketika Nabi baru beberapa bulan sampai di Madinah. Pada saat itu, Islam belum menjadi agama mayoritas. Berdasarkan sensus yang dilakukan ketika pertama kali Nabi berada di Madinah itu, diketahui bahwa jumlah umat Islam hanya 1.500 dari 10.000 penduduk Madinah. Sementara orang Yahudi berjumlah 4.000 orang dan orang-orang Musyrik berjumlah 4.500 orang. ${ }^{21}$

Dikatakan dalam piagam tersebut misalnya bahwa seluruh penduduk Madinah, apapun latar belakang etnis dan agamanya, harus saling melindungi tatkala salah satu di antara mereka mendapatkan serangan dari luar. Sekiranya kaum Yahudi mendapatkan serangan dari luar, maka umat Islam membantu menyelamatkan nyawa dan harta benda mereka. Begitu juga, tatkala umat Islam diserang pihak luar, maka kaum Yahudi ikut melindungi dan menyelamatkan. Pada paragraf awal Piagam itu tercantum "Jika seorang pendeta atau pejalan berlindung di gunung atau lembah atau gua atau bangunan atau dataran raml atau Radnah (nama sebuah desa di Madinah) atau gereja, maka aku (Nabi) adalah pelindung di belakang mereka dari setiap permusuhan terhadap mereka demi jiwaku, para pendukungku, para pemeluk agamaku dan para pengikuntuku, sebagaimana mereka (kaum Nashrani) itu adalah rakyatku dan anggota perlindunganku”.Apa yang dilakukan Nabi Muhammad di Madinah ini menginspirasi Umar ibn Khattab untuk membuat traktat serupa di Yerusalem, dikenal dengan "Piagam Aelia", ketika Islam menguasai wilayah ini. Piagam ini berisi "jaminan keselamatan dari penguasa Islam terhadap penduduk Yerusalem, yang beragama non-Islam sekalipun. Salah satu penggalan paragrafnya berbunyi: "Inilah jaminan keamanan yang diberikan Abdullah, Umar, Amirul Mukminin kepada penduduk Aelia: Ia menjamin keamanan mereka untuk jiwa dan harta mereka, dan untuk gereja-gereja dan salib-salib mereka, dalam keadaan sakit maupun sehat, dan untuk agama mereka secara keseluruhan. Gereja-gereja mereka tidak akan diduduki dan tidak

20 Ensiklopedi Tematis Dunia Islam, Dinamika Masa Kini, 2002, Ichtiar Baru van Hoeve, Jakarta, hal. 214 $21 \mathrm{http} / /$ islamlib.com/id/artikel/islam-dan-pluralitasisme-agama 
pula dirusak, dan tidak akan dikurangi sesuatu apapun dari gereja-gereja itu dan tidak pula dari lingkungannya, serta tidak dari salib mereka, dan tidak sedikitpun dari harta kekayaan mereka (dalam gereja-gereja itu). Mereka tidak akan dipaksa meninggalkan agama mereka, dan tidak seorang pun dari mereka boleh diganggu ${ }^{22}$ ".

Muhammad Rasyîd Ridlâ menuturkan bahwa Umar ibn Khattab pernah mengangkat salah seorang stafnya dari Romawi. Ini juga dilakukan Utsman ibn Affan, Ali ibn Abi Thalid, rajaraja Bani Umayyah hingga suatu waktu Abdul Malik ibn Marwan menggantikan staf orang Romawi ke orang Arab. Daulah Abbasiyah juga banyak mengangkat staf dari kalangan Yahudi, Nashrani, dan Shabiun. Daulah Utsmaniyah juga mengangkat duta besar di negara-negara asing dari kalangan Nashrani ${ }^{23}$

Fakta ini membenarkan sebuah pandangan bahwa peperangan pada zaman Nabi dipicu karena persoalan ekonomi-politik daripada soal agama atau keyakinan. Ini bisa dimaklumi karena al-Qur'an sejak awal mendorong terwujudnya kebebasan beragama dan berkeyakinan. Al-Qur'an tak memaksa seseorang memeluk Islam. Allah berfirman (QS, al-Baqarah [2]: 256), lâ ikrâha fî al-dîn (tak ada paksaan dalam soal agama).

Di ayat lain (QS, al-Kafirun [106]: 6) disebuntukan, lakum dinukum wa liya dini [untukmulah agamamu, dan untukkulah agamaku]. Al-Qur'an memberikan kebebasan kepada manusia untuk beriman dan kafir [Faman syâa falyumin waman syâa falyakfur] (QS, al-Kahfi [18]: 29).

\section{Penutup}

Berangkat dari uraian diatas dapat diketahui, bahwa Islam sangat indah dan menakjubkan yang selalu menjaga toleran, kedamaian, kerukunan, keadilan dan keanekaragaman. Seperti perjajian tertulis oleh Nabi Muhammad Saw, yang lebih populer disebut "Piagam Madinah" yang berisi, tentang pengakuan eksistensi agama dan akidah masing-masing, kesepakatan untuk sama-sama membela negara madinah dan mempertahankannya dari bahaya luar. ${ }^{24}$

Untuk keutuhan umat ini, Piagam Madinah menegaskan pentingnya persaudaraan dan persatuan diwujudkan dalam kehidupan antar golongan dengan menjalin kerjasama untuk mencapai tujuan umum bersama dalam kehidupan sosial. Oleh Karena itu, Islam sangat menghargai, menghormati keberanekaragaman di masyarakat dunia yang sifatnya heterogen. Dengan Piagam Madinah ini, Nabi saw telah menerapkan prinsip-prinsip toleransi dan mengakui tentang adanya pluralitas/keberagaman umat manusia.

22 Ensiklopedi Tematis Dunia Islam.hal. 215

$23 \mathrm{http} / / /$ islamlib.com/id/artikel/islam-dan-pluralitasisme-agama

24 Mundzier Saputra,hal.84 
92 Joko Widodo

\section{BIBLIOGRAFI}

Abul Hasan Ali Nadwi, Islam dan Dunia, penerjemah. Adang affandi,2008, Angkasa Bandung

Christine Huda Dodge, Kebenaran Islam, 2006. PT. Anindya Mitra Internasional,Yogjakarta

Ensiklopedi Tematis Dunia Islam, Dinamika Masa Kini, 2002, Ichtiar Baru van Hoeve, Jakarta,

Hadist Sohih Muslim, penerjemah, H. Fahcrudin,

Mamud Hamdi Zaqzuq, Islam dan Tantangan dalam Menghadapi Pemikiran barat, Penerjemah Ahmad Sodikin, 2003, CV Pustaka Setia, Bandung

M.Tuwah, subardi Dkk, Islam Humanis, 2001,PT Moyo Segoro Agung Jakarta

Muhammad Ibrahim al-Hamd, Keistimewaan aqidah Islam, Penerjemah, Abu Salma,2009, Islam House $\mathrm{H}$

Mundzier Suparta, Islamic Mulicultural Education Sebuah Refleksi atas Pendidikan Agama Islam di Indonesia,2008,Al-Ghazali Center, Jakarta

Nasruddin Razak, Dienul Islam, 1973, PT Alma’arif Bandung

Suparman Usman, Hukum Islam Asas-asas dan pengantar Studi Hukum Islam dalam Tata Hukum Indonesia,2001, Gaya media Pratama, Jakarta

http://islamlib.com/id/artikel/islam-dan-pluralitasisme-agama)

http://media-islam.or.id/2008/09/15/inti-ajaran-islam-iman-islam-dan-ihsan/

http://blog.re.or.id/karakteristik-ajaran-islam.htm)

http://www.christianpost.co.id/opini/20090728/4891/pluralitas-keagamaan-asset-atauliability/ 